\title{
Nitric oxide generation mediated by $\beta$-adrenoceptors is impaired in platelets from patients with Type 2 diabetes mellitus
}

\author{
L. R. Queen ${ }^{1,2}$, Y. Ji ${ }^{1}$, I. Goubareva ${ }^{1}$, A. Ferro ${ }^{1}$ \\ ${ }^{1}$ GKT School of Medicine (Cardiovascular Division), King's College London, London, UK \\ ${ }^{2}$ New Hunt's House, GKT School of Medicine (Cardiovascular Division), King's College London, Guy's Hospital, London, UK
}

\begin{abstract}
Aims/hypothesis. Type 2 diabetic patients have been shown to have reduced basal platelet nitric oxide synthase activity, which is a possible contributor to the vascular complications seen in the disease. We investigated platelet nitric oxide generation stimulated by $\beta$-adrenoceptors and adenylyl cyclase in Type 2 diabetic patients and control subjects.

Methods. Platelets isolated from blood taken from nine Type 2 diabetic patients and nine healthy control subjects of similar age were treated with isoproterenol $1 \mu \mathrm{mol} / \mathrm{l}$, forskolin $1 \mu \mathrm{mol} / \mathrm{l}$ or vehicle. Platelet nitric oxide synthase activity was measured by L- $\left[{ }^{3} \mathrm{H}\right]$-arginine to L- $\left[{ }^{3} \mathrm{H}\right]$-citrulline conversion, cyclic GMP content by radioimmunoassay, and nitric oxide synthase type 3 expression by western blotting.

Results. Basal platelet nitric oxide synthase activity was lower in diabetic patients than in control subjects $\left(0.01 \pm 0.02\right.$ pmol L-citrulline $/ 10^{8}$ platelets, compared with $0.12 \pm 0.05 ; p<0.05)$, although no corresponding difference was seen in basal platelet cyclic GMP $\left(0.61 \pm 0.39\right.$ and $0.13 \pm 0.22$ pmol cyclic GMP $/ 10^{8}$ platelets respectively; $p=0.37$ ). In control subjects iso-
\end{abstract}

proterenol $1 \mu \mathrm{mol} / \mathrm{l}$ and forskolin $1 \mu \mathrm{mol} / \mathrm{l}$ increased platelet nitric oxide synthase activity (to $0.27 \pm 0.08$ and $0.27 \pm 0.07 \mathrm{pmol}$ L-citrulline $/ 10^{8}$ platelets respectively; $p<0.05$ for each in comparison with basal) and cyclic GMP (to $1.84 \pm 0.41$ and $1.86 \pm 0.48 ; p<0.05$ for each in comparison with basal). This effect was not achieved in diabetic patients. Isoproterenol- and forskolin-stimulated cyclic GMP correlated inversely with plasma glucose and $\mathrm{HbA}_{1 \mathrm{c}}$. Platelet nitric oxide synthase type 3 expression was not different in control and diabetic subjects and was not changed by acute exposure of platelets to isoproterenol.

Conclusions/interpretation. Nitric oxide generation stimulated by $\beta$-adrenoceptors and adenylyl cyclase is impaired in platelets of people with Type 2 diabetes mellitus, with no corresponding change in nitric oxide synthase type 3 expression. It is possible that this impairment contributes to the thrombotic and atherosclerotic complications of Type 2 diabetes. [Diabetologia (2003) 46:1474-1482]

Keywords Type 2 diabetes mellitus, platelets, nitric oxide, $\beta$-adrenoceptors, cyclic GMP, nitric oxide synthase.
Received: 3 March 2003 / Revised: 30 June 2003

Published online: 23 October 2003

(C) Springer-Verlag 2003

Corresponding author: L. R. Queen, Room 2.36 New Hunt's House, GKT School of Medicine (Cardiovascular Division), King's College London, Guy's Hospital, London, SE1 1UL UK E-mail: lindsay.queen@kcl.ac.uk

Abbreviations: $\beta \mathrm{AR}, \beta$-adrenoceptors; GFP, gel-filtered plate-

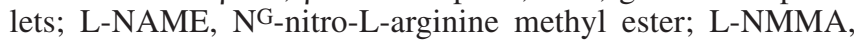
$\mathrm{NG}^{-}$-monomethyl-L-arginine; $\mathrm{NO}$, nitric oxide; NOS2, nitric oxide synthase type 2 ; NOS3, nitric oxide synthase type 3 .
Generated by endothelium and platelets, nitric oxide (NO) is an important regulator of platelet function, inhibiting their aggregation [1] and their adhesion to the vascular endothelium [2]. Platelets express NO synthase type 3 (NOS3, endothelial-type NOS) and NO synthase type 2 (NOS2, inducible-type NOS), with NOS3 being predominant and NOS2 present only in much smaller quantities [3]. Platelet-derived NO, synthesised by NOS3, could act as a negative feedback mechanism to regulate platelet activation after a proaggregatory stimulus [4]. It also plays an important role in the regulation of platelet recruitment [5]. Re- 
cently we reported that the stimulation of $\beta$-adrenoceptors ( $\beta \mathrm{AR}$ ) through an increase of cyclic AMP generates NO in human platelets and that this plays a role in regulating platelet adhesion to vascular endothelium [6]. Impairment of the L-arginine/NO pathway in endothelium and/or platelets is common in many cardiovascular disorders, including diabetes mellitus [7, 8, 9, 10, 11, 12]. It is, however, uncertain whether such impairment plays a central role in, or occurs as a result of vascular disease in these conditions.

Platelet dysfunction is a common feature of diabetes mellitus $[13,14]$ and much of the morbidity and mortality of Type 2 diabetes relates to atheromatous disease and its thrombotic complications. A lack of biologically active NO in such conditions could predispose to platelet adhesion to the endothelium and to the exposed subintima in ruptured atheromatous plaques, with subsequent thrombus formation. However, it is likely that loss of stimulated NO production by platelets is equally or more important under conditions predisposing to platelet activation, such as acute coronary syndromes or myocardial infarction. In such conditions sympathetic activation could increase circulating norepinephrine and epinephrine to concentrations high enough to activate $\beta$ AR to an important degree [15] and give rise to NO generation by platelets. Loss of $\beta A R$-mediated NO generation in platelets would be expected to predispose to platelet thrombus formation in people with cardiovascular disease.

Although platelets are anucleate cells, they retain small amounts of mRNA $[16,17]$ capable of undergoing translation. This process could in turn affect expression of proteins such as NOS3. Differential expression of NOS3 in megakaryocytes from Type 2 diabetic patients and healthy subjects could also give rise to differences in NOS3 expression in mature platelets. Alternatively, expression of proteins in platelets could be affected by alterations in their rate of breakdown. Insulin and glucose concentrations have also been shown to affect expression of NOS in different cells $[18,19]$. Moreover, in streptozotocin-induced diabetic rats, NOS3 expression in aortic endothelial cells has been found to be more than three times higher than in control animals [20]. By analogy, it is possible that diabetes affects NOS3 expression in human platelets.

Our study was designed to investigate whether stimulated NO generation, in response to $\beta$ AR activation or to an increase in cyclic AMP, is impaired in platelets from patients with Type 2 diabetes mellitus. We also wished to measure NOS3 expression, both basally and after $\beta$ AR stimulation, in platelets from control and Type 2 diabetic subjects.

\section{Subjects and methods}

Subject recruitment. We recruited nine patients with Type 2 diabetes mellitus from the Diabetic and Endocrine Clinic at St Thomas' Hospital, London. These patients were controlling
Table 1. Medication taken by Type 2 diabetic subjects

\begin{tabular}{ll}
\hline Medication & $\begin{array}{l}\text { Number } \\
\text { of } \\
\text { patients }\end{array}$ \\
\hline None & 2 \\
Metformin alone & 2 \\
Metformin + Glibenclamide & 1 \\
Metformin + Glibenclamide + Diclofenac & 1 \\
Metformin + angiotensin converting enzyme inhibitors & 2 \\
Metformin + Simvastatin + Doxazosin & 1 \\
\hline
\end{tabular}

Table 2. Characteristics of control and Type 2 diabetic subjects

\begin{tabular}{lcc}
\hline & $\begin{array}{l}\text { Control } \\
\text { subjects }\end{array}$ & $\begin{array}{c}\text { Diabetic } \\
\text { subjects }\end{array}$ \\
\hline Age & $54.2 \pm 1.8$ & $58.8 \pm 2.1$ \\
Men/Women & $7 / 2$ & $5 / 4$ \\
Total cholesterol (mmol/l) & $6.2 \pm 0.3$ & $6.7 \pm 1.4$ \\
HDL cholesterol (mmol/l) & $1.7 \pm 0.2$ & $1.3 \pm 0.1$ \\
LDL cholesterol (mmol/l) & $3.8 \pm 0.4$ & $3.3 \pm 0.4$ \\
Total triglycerides $(\mathrm{mmol} / \mathrm{l})$ & $1.3 \pm 0.2$ & $2.4 \pm 0.5$ \\
Glucose $(\mathrm{mmol} / \mathrm{l})_{\text {HbA }_{1 \mathrm{c}}(\%)}$ & $5.2 \pm 0.3$ & $11.1 \pm 1.3^{* *}$ \\
\hline
\end{tabular}

All values are for fasting blood samples and are expressed as means \pm SEM of nine different subjects in each group. $* * p<0.01$ vs. control group

the disease either by diet alone or with the additional use of oral hypoglycaemic drugs. They had no clinical evidence of macro- or microvascular complications of diabetes, and no patients were taking anti-platelet drugs. The medication taken by the diabetic patients is summarised in Table 1 . We recruited nine healthy control subjects of a similar age and sex distribution from hospital staff. None of the control subjects had taken any medication in the 5 days prior to the study. Blood was drawn in the fasting state for the measurement of glucose, lipid profile and $\mathrm{HbA}_{1 \mathrm{c}}$ (Table 2). Ethical approval for the study was granted by the Research Ethics Committee, St Thomas' Hospital, London, United Kingdom and informed verbal consent was obtained from all participants.

Platelet preparation. Using a 19-gauge Butterfly needle (Abbott, Sligo, Ireland), $120 \mathrm{ml}$ venous blood was obtained from an antecubital vein and collected into trisodium citrate $(0.38 \%$ final concentration). Platelet-rich plasma, prepared by centrifuging the whole blood ( $\left.8 \mathrm{~min}, 800 \times g, 20^{\circ} \mathrm{C}\right)$, was applied to a Sepharose CL-2B gel column (Amersham Biosciences UK, Little Chalfont, UK). Gel-filtered platelets (GFP) were eluted with and collected in sodium Tyrode buffer (final composition in mmol/l: $\mathrm{NaCl} 125.0$, glucose 5.6, HEPES 5.0, $\mathrm{KCl} \mathrm{2.8,}$ $\left.\mathrm{KH}_{2} \mathrm{PO}_{4} 0.8, \mathrm{MgCl}_{2} 0.4 ; \mathrm{pH} 7.4\right)$. The platelet count was measured in the eluate using a Coulter counter (Gen.S System 2, Beckman Coulter, High Wycombe, UK).

Platelet NOS activity. NOS activity in platelets was assessed by measuring the conversion of $\mathrm{L}-\left[{ }^{3} \mathrm{H}\right]$-arginine to $\mathrm{L}-\left[{ }^{3} \mathrm{H}\right]$-citrulline [6]. Briefly, aliquots of GFP $(1 \mathrm{ml})$ were incubated with $0.037 \mathrm{MBq} \mathrm{L}-\left[{ }^{3} \mathrm{H}\right]$-arginine in the absence or presence of the NOS inhibitor $\mathrm{N}^{\mathrm{G}}$-nitro-L-arginine methyl ester (L-NAME; $100 \mu \mathrm{mol} / \mathrm{l}$ ). This was done for $15 \mathrm{~min}$ at $37^{\circ} \mathrm{C}$. Isoproterenol 
$1 \mu \mathrm{mol} / \mathrm{l}$, forskolin $1 \mu \mathrm{mol} / \mathrm{l}$ or vehicle was added and incubated for a further $25 \mathrm{~min}$ at $37^{\circ} \mathrm{C}$. The reaction was ended by adding ice-cold sodium Tyrode containing L-NAME ( $5 \mathrm{mmol} / \mathrm{l})$. The platelets were then pelleted by centrifugation $(20 \mathrm{~min}, 2000 \times g$, $\left.4^{\circ} \mathrm{C}\right)$. Platelet lysates were prepared and mixed with an excess of Dowex cation exchange resin $\left(\mathrm{Na}^{+}\right.$form) to adsorb L-arginine. L- $\left[{ }^{3} \mathrm{H}\right]$-citrulline in the supernatant was measured by liquid scintillation counting using a Wallac 1215 Rackbeta counter (PerkinElmer Life Sciences, Beaconsfield, UK). L-citrulline formation was calculated using the following equation:

pmol $L-$ citrulline $=\frac{c p m}{c p m_{s}} \times 14$

where cpm is the counts per minute of the unknown sample, and $\mathrm{cpm}_{\mathrm{s}}$ is counts per minute of the standard.

All standards contained $0.037 \mathrm{MBq} \mathrm{L}-\left[{ }^{3} \mathrm{H}\right]$-arginine, corresponding to 14 pmol. It was assumed that $\mathrm{L}-\left[{ }^{3} \mathrm{H}\right]$-arginine is converted to L- $\left[{ }^{3} \mathrm{H}\right]$-citrulline with 1 to 1 stoichiometry. NOS activity was taken as the difference in calculated L-citrulline formation when co-incubated with and without L-NAME.

In a subset of healthy control subjects, the effect of acute hyperglycaemia on $\mathrm{L}-\left[{ }^{3} \mathrm{H}\right]$-citrulline production by platelets in vitro was examined. GFP were eluted with and collected either in normal sodium Tyrode containing $5.6 \mathrm{mmol} / \mathrm{l}$ glucose, or in high-glucose sodium Tyrode containing $11.2 \mathrm{mmol} / \mathrm{l}$ glucose (sodium Tyrode composition, see above). L- $\left[{ }^{3} \mathrm{H}\right]$-citrulline production was measured after incubation, with either vehicle control, isoproterenol $1 \mu \mathrm{mol} / 1$ or forskolin $1 \mu \mathrm{mol} / 1\left(25 \mathrm{~min}, 37^{\circ} \mathrm{C}\right)$.

To confirm that platelet function was not compromised during preparation, separate experiments were performed on platelets from healthy control subjects. The platelets were isolated and after stimulation with collagen $8 \mathrm{mg} / \mathrm{ml}(25 \mathrm{~min}$, $37^{\circ} \mathrm{C}$ ) in the absence or presence of the NOS inhibitor $\mathrm{NG}_{-}$ monomethyl-L-arginine (L-NMMA) $100 \mu \mathrm{mol} / 1$, L-[3 $\mathrm{H}]$-citrulline production was measured as described above.

Platelet cyclic GMP measurement. In order to confirm that the NOS activity measured truly reflects biologically available NO, cyclic GMP was measured in platelets basally and in response to $\beta A R$ stimulation or adenylyl cyclase activation. Aliquots of GFP (1 ml) were incubated with 3-isobutyl-1-methylxanthine $500 \mu \mathrm{mol} / \mathrm{l}$ in the absence or presence of L-NAME $100 \mu \mathrm{mol} / \mathrm{l}$. Incubation took place for $15 \mathrm{~min}$ at $37^{\circ} \mathrm{C}$. Isoproterenol $1 \mu \mathrm{mol} / \mathrm{l}$, forskolin $1 \mu \mathrm{mol} / \mathrm{l}$ or vehicle was added and the incubation continued for a further $25 \mathrm{~min}$. The reaction was ended by adding $1 \mathrm{ml}$ ice-cold perchloric acid $0.3 \mathrm{~mol} / \mathrm{l}$. The platelets were lysed by sonication for $30 \mathrm{~min}$ and by rapid freezing $\left(-20^{\circ} \mathrm{C}\right)$ and thawing. Cell debris was pelleted by centrifugation $\left(20 \mathrm{~min}, 2000 \times g, 4^{\circ} \mathrm{C}\right)$. The supernatants containing cyclic GMP were collected and stored at $-20^{\circ} \mathrm{C}$ until ready for assay using a cyclic GMP radioimmunoassay kit (Amersham Biosciences, Buckinghamshire, UK). The cyclic GMP attributable to NO activity ("NO-attributable cyclic GMP") was taken as the difference in measured cyclic GMP when co-incubated with and without L-NAME.

Measurement of NOS expression. Aliquots of GFP (1 ml) were incubated for $15 \mathrm{~min}$ at $37^{\circ} \mathrm{C}$ with L-NAME $100 \mu \mathrm{mol} / \mathrm{l}$ or vehicle. Isoproterenol $1 \mu \mathrm{mol} / 1$, forskolin $1 \mu \mathrm{mol} / \mathrm{l}$ or vehicle was added and the incubation continued for a further $25 \mathrm{~min}$. The reaction was ended by placing the tubes on ice. The platelets were then pelleted $\left(20 \mathrm{~min}, 2000 \times g, 4^{\circ} \mathrm{C}\right)$ and lysed by adding $100 \mu \mathrm{l}$ lysis buffer (final composition in mmol/l: $\mathrm{NaCl}$ 150; TRIS 25; Na fluoride 50; Na orthovanadate 1.0; phenylmethylsulfonyl fluoride 1.0; aprotinin $1 \mu \mathrm{g} / \mathrm{ml}$; leupeptin $10 \mu \mathrm{g} / \mathrm{ml} ; \mathrm{pH}$ 7.6). Next they were subjected to SDS-PAGE using a $7.5 \%$ acrylamide gel, followed by western blotting.

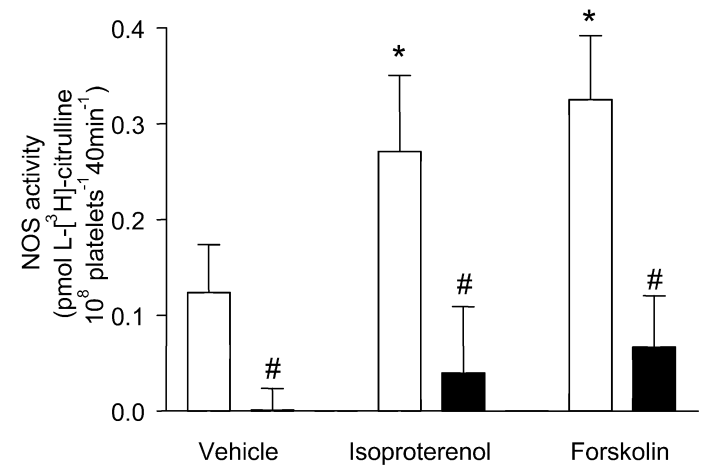

Fig. 1. NOS activity in platelets from control and Type 2 diabetic subjects. NOS activity (in pmol L- $\left[{ }^{3} \mathrm{H}\right]$-citrulline $/ 10^{8}$ platelets over $40 \mathrm{~min}$ ) was calculated as the difference between L-citrulline production in the absence and presence of L-NAME $100 \mu \mathrm{mol} / \mathrm{l}$. Responses are shown to vehicle, isoproterenol $1 \mu \mathrm{mol} / \mathrm{l}$ and forskolin $1 \mu \mathrm{mol} / \mathrm{l}$. Control subjects are represented by open bars and Type 2 diabetic subjects by solid bars. Values are means \pm SEM of measurements in nine subjects per group. $* p<0.05$ vs vehicle; $\# p<0.05$ vs corresponding values in control subjects

Protein bands on the gel were transferred to a polyvinylidene fluoride membrane for $3 \mathrm{~h}$ at $0.8 \mathrm{~mA}$ per $\mathrm{cm}^{2}$. The membranes were blocked overnight at $4^{\circ} \mathrm{C}$ in PBS-Tween $20(0.02 \%)$ containing 3\% BSA. The next day they were incubated for $1 \mathrm{~h}$ with NOS3 affinity-purified rabbit polyclonal antibody (Santa Cruz Biotechnology, Santa Cruz, Calif., USA; 1:500 dilution in PBS-Tween 20 containing $0.3 \%$ BSA). After several washes with PBS-Tween 20, goat anti-rabbit horseradish peroxidaseconjugated IgG secondary antibody (Perbio Science UK, Tattenhall, UK; 1:10,000 dilution) was added and the membrane incubated at room temperature for $1 \mathrm{~h}$. Excess antibody was removed by washing several times with PBS-Tween 20. The membranes were covered for 1 min with ECL western blotting detection reagents, then exposed to Hyperfilm for up to $5 \mathrm{~min}$. The films were scanned into Microsoft Windows 95 Paint software using a ScanJet 3400C scanner (Hewlett Packard, Palo Alto, Calif., USA). The area and density of each band on each film were measured using Image J $1.25 \mathrm{~s}$ software (National Institutes of Health, Bethesda, USA).

Statistical analysis. All NOS activity and cyclic GMP experiments were carried out in duplicate and the mean of each duplicate used for further statistical analysis. Data were analysed using one-way ANOVA with or without repeated measures as appropriate. All data are expressed as mean \pm SEM. Relationships between NOS activity or cyclic GMP and indices of glycaemic control were examined by linear regression analysis (GraphPad Prism 3.0). A $p$ value of less than 0.05 (two-tailed) was considered to be statistically significant throughout the study.

\section{Results}

Platelet NOS activity. In the control group $(n=9)$, basal NOS activity was $0.11 \pm 0.05$ pmol L-citrulline/ $10^{8}$ platelets over $40 \mathrm{~min}$. This was increased two to threefold by isoproterenol $1 \mu \mathrm{mol} / \mathrm{l}$ and forskolin $1 \mu \mathrm{mol} / 1$ ( $p<0.05$ for each in comparison with basal; Fig. 1). In the group of diabetic patients $(n=9)$, basal 


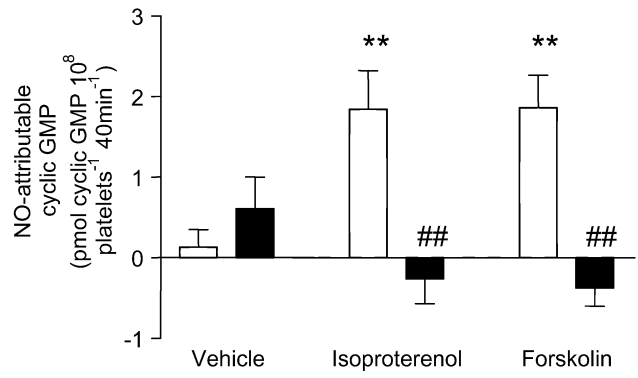

Fig. 2. Cyclic GMP attributable to the action of NO in control and Type 2 diabetic subjects. Data, expressed as pmol cyclic GMP/10 $/ 0^{8}$ platelets over $40 \mathrm{~min}$, are shown as the difference between cyclic GMP measured in the absence and presence of L-NAME $100 \mu \mathrm{mol} / \mathrm{l}$. Responses are shown to vehicle, isoproterenol $1 \mu \mathrm{mol} / \mathrm{l}$ and forskolin $1 \mu \mathrm{mol} / \mathrm{l}$. Open bars represent control subjects and solid bars Type 2 diabetic subjects. Values are means \pm SEM of measurements in nine subjects per group. $* * p<0.01$ vs vehicle; \#\# $p<0.01$ vs corresponding values in control subjects

NOS activity was significantly lower than in the control group at $0.01 \pm 0.02$ pmol L-citrulline $/ 10^{8}$ platelets $(p<0.05$ in comparison with control group). There was no significant rise in NOS activity in response to isoproterenol $1 \mu \mathrm{mol} / \mathrm{l}$ or forskolin $1 \mu \mathrm{mol} / \mathrm{l}(p=0.71$ and $p=0.39$ respectively, in comparison with basal; Fig. 1).

In platelets from healthy subjects studied in vitro and incubated with $5.6 \mathrm{mmol} / \mathrm{l}$ glucose, isoproterenol $1 \mu \mathrm{mol} / 1$ and forskolin $1 \mu \mathrm{mol} / 1$ increased $\mathrm{L}-\left[{ }^{3} \mathrm{H}\right]-$ citrulline production $(48.5 \pm 8.4 \%$ and $45.8 \pm 18.2 \%$ increase respectively, $n=5, p<0.05$ for each in comparison with basal). In contrast, platelets incubated with $11.2 \mathrm{mmol} / \mathrm{l}$ glucose did not significantly increase $\mathrm{L}-\left[{ }^{3} \mathrm{H}\right]$-citrulline production in response to isoproterenol $1 \mu \mathrm{mol} / 1$ or forskolin $1 \mu \mathrm{mol} / \mathrm{l}(15.2 \pm 17.0 \%$ and $3.81 \pm 9.9 \%$ increase respectively).

In the control experiments done in vitro on platelets from healthy volunteers $(n=5)$ basal L- $\left[{ }^{3} \mathrm{H}\right]$-citrulline production was $0.059 \pm 0.002$ pmol L-citrulline/ $10^{8}$ platelets. This was reduced in the presence of L-NMMA $100 \mu \mathrm{mol} / \mathrm{l}$ to $0.044 \pm 0.002 \mathrm{~L}$-citrulline/ $10^{8}$ platelets $(p<0.01)$. Collagen $8 \mathrm{mg} / \mathrm{ml}$ increased $\mathrm{L}-\left[{ }^{3} \mathrm{H}\right]$-citrulline production above basal concentrations to $0.076 \pm 0.006 \mathrm{pmol}$ L-citrulline $/ 10^{8}$ platelets $(p<0.05)$.

Platelet cyclic GMP. In control subjects $(n=9)$ basal cyclic GMP attributable to NO was $0.13 \pm 0.22 \mathrm{pmol}$ cyclic GMP $/ 10^{8}$ platelets over $40 \mathrm{~min}$; at $0.61 \pm$ 0.39 pmol cyclic GMP $/ 10^{8}$ platelets it was not different in the diabetic subjects $(n=9 ; p=0.37)$. Isoproterenol $1 \mu \mathrm{mol} / 1$ and forskolin $1 \mu \mathrm{mol} / 1$ increased cyclic GMP attributable to NO by more than tenfold above basal in the control subjects $(p<0.01$ for each in comparison with basal; Fig. 2). In the diabetic patients, by contrast, neither isoproterenol nor forskolin had any significant effect ( $p=0.15$ and $p=0.11$ respectively, in comparison to basal; Fig. 2).
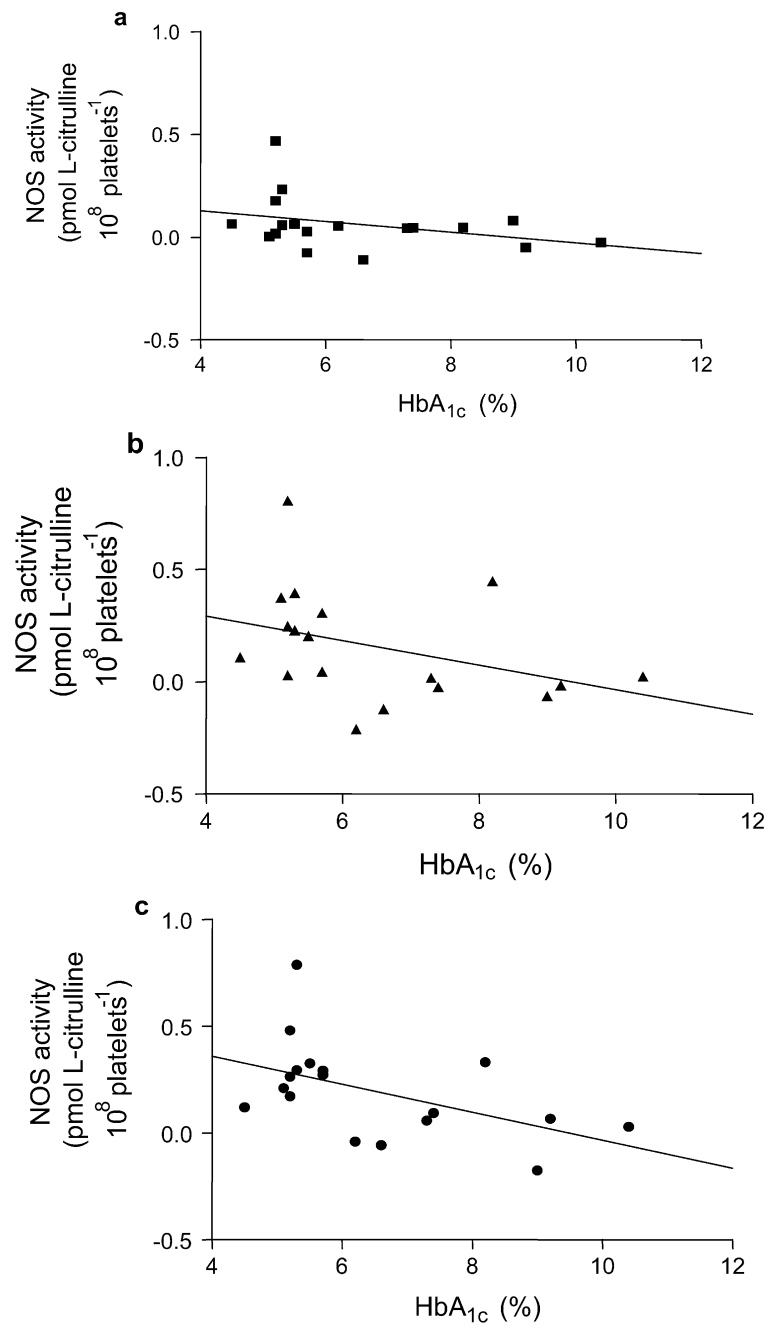

Fig. 3a-c. Linear regression analysis of the relationship between NOS activity and $\mathrm{HbA}_{1 \mathrm{c}}$. The figure shows (a) basal $\left(\boldsymbol{\square}, r^{2}=0.11 ; p=0.16\right),(\mathbf{b})$ isoproterenol-stimulated $\left(\boldsymbol{\Delta}, r^{2}=0.14\right.$; $p=0.12)$ and (c) forskolin-stimulated (,$\left.r^{2}=0.25 ; p=0.03\right)$ NOS activity in relation to $\mathrm{HbA}_{1 \mathrm{c}}$ in the 18 subjects studied

Correlation between platelet NO generation and glycaemic status. No significant correlation was found between basal or isoproterenol-stimulated NOS activity and $\mathrm{HbA}_{1 \mathrm{c}}(p=0.16$ and $p=0.12$ respectively; Fig. 3a,b). However, there was an inverse correlation between forskolin-stimulated NOS activity and $\mathrm{HbA}_{1 \mathrm{c}}$ $(p<0.05$; Fig. 3c). Similarly, no significant correlation was found between basal cyclic GMP attributable to $\mathrm{NO}$ and $\mathrm{HbA}_{1 \mathrm{c}}$ values ( $p=0.14$; Fig. $4 \mathrm{a}$ ), whereas both isoproterenol- and forskolin-stimulated cyclic GMP concentrations attributable to NO were inversely correlated to $\mathrm{HbA}_{1 \mathrm{c}}$ values ( $p<0.02$ for each; Fig. $4 \mathrm{~b}, \mathrm{c}$ ).

With regard to plasma glucose concentrations no correlation was found between them and basal or isoproterenol-stimulated NOS activity $(p=0.06$ and $p=0.08$ respectively; Fig. 5a,b). In contrast, there was an inverse correlation between forskolin-stimulated NOS activity and plasma glucose concentrations $(p<0.05$; Fig. 5c). Similarly, no significant correlation 

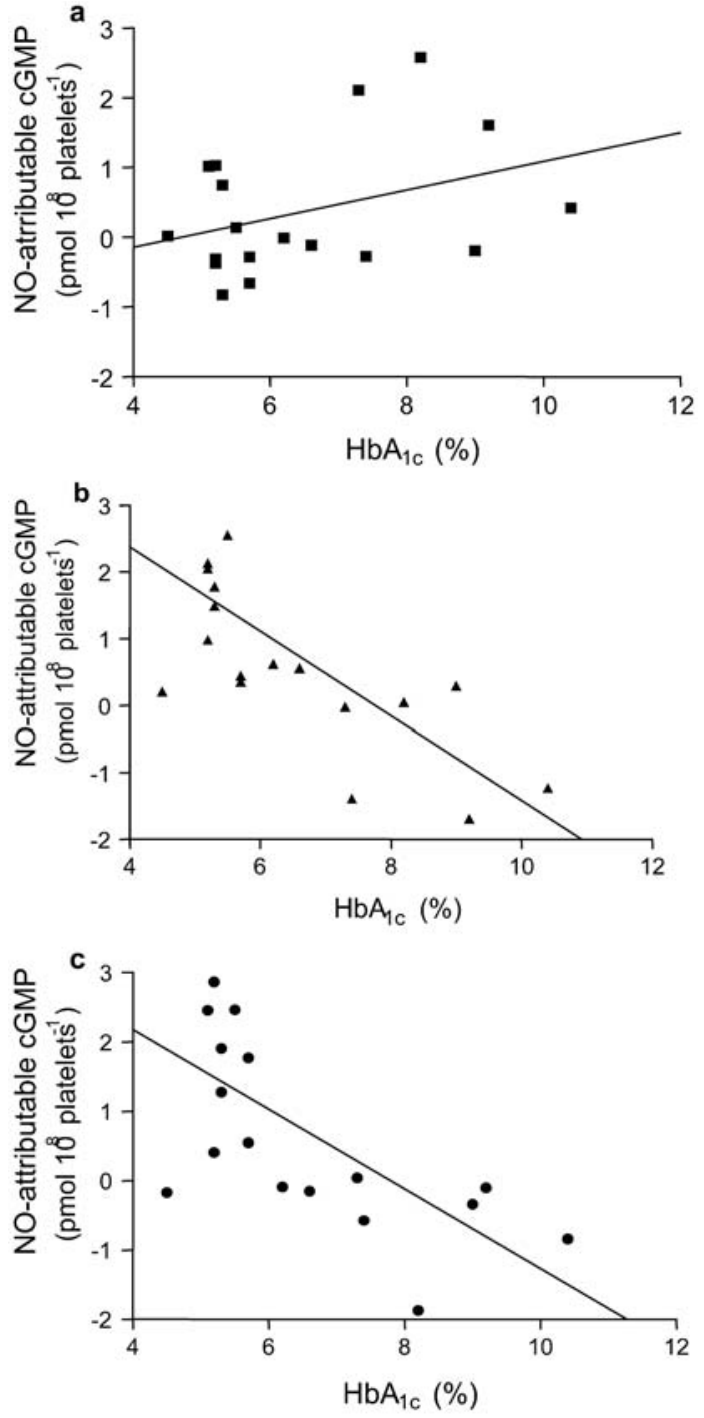

Fig. 4a-c. Linear regression analysis of the relationship between NO-attributable cyclic GMP concentrations and $\mathrm{HbA}_{1 \mathrm{c}}$. The figure shows (a) basal $\left(\mathbf{a}, r^{2}=0.13 ; p=0.14\right)$, (b) isoproterenol-stimulated $\left(\boldsymbol{\Lambda}, r^{2}=0.46 ; p<0.01\right)$ and $(\mathbf{c})$ forskolin-stimulated $\left(O, r^{2}=0.43 ; p<0.01\right)$ NO-attributable cyclic GMP concentrations in relation to $\mathrm{HbA}_{1 \mathrm{c}}$ in the 18 subjects studied. cGMP=cyclic GMP

was found between basal cyclic GMP attributable to $\mathrm{NO}$ and plasma glucose concentration ( $p=0.46$; Fig. 6a). However, an inverse correlation was found between isoproterenol- and forskolin-stimulated cyclic GMP attributable to NO and plasma glucose concentrations $(p<0.02$ for each; Fig. $6 \mathrm{~b}, \mathrm{c})$.

NOS3 expression in platelets from control and Type 2 diabetic subjects. In vehicle-treated platelets taken from healthy subjects and diabetic patients a predominant band of $130 \mathrm{M}_{\mathrm{r}}$ was found by probing with an anti-NOS3 rabbit polyclonal antibody (Fig. 7a); this is the reported molecular weight of NOS3 in platelets. Platelet NOS3 expression, calculated as the product of the area and density of each band ("band quantity"),
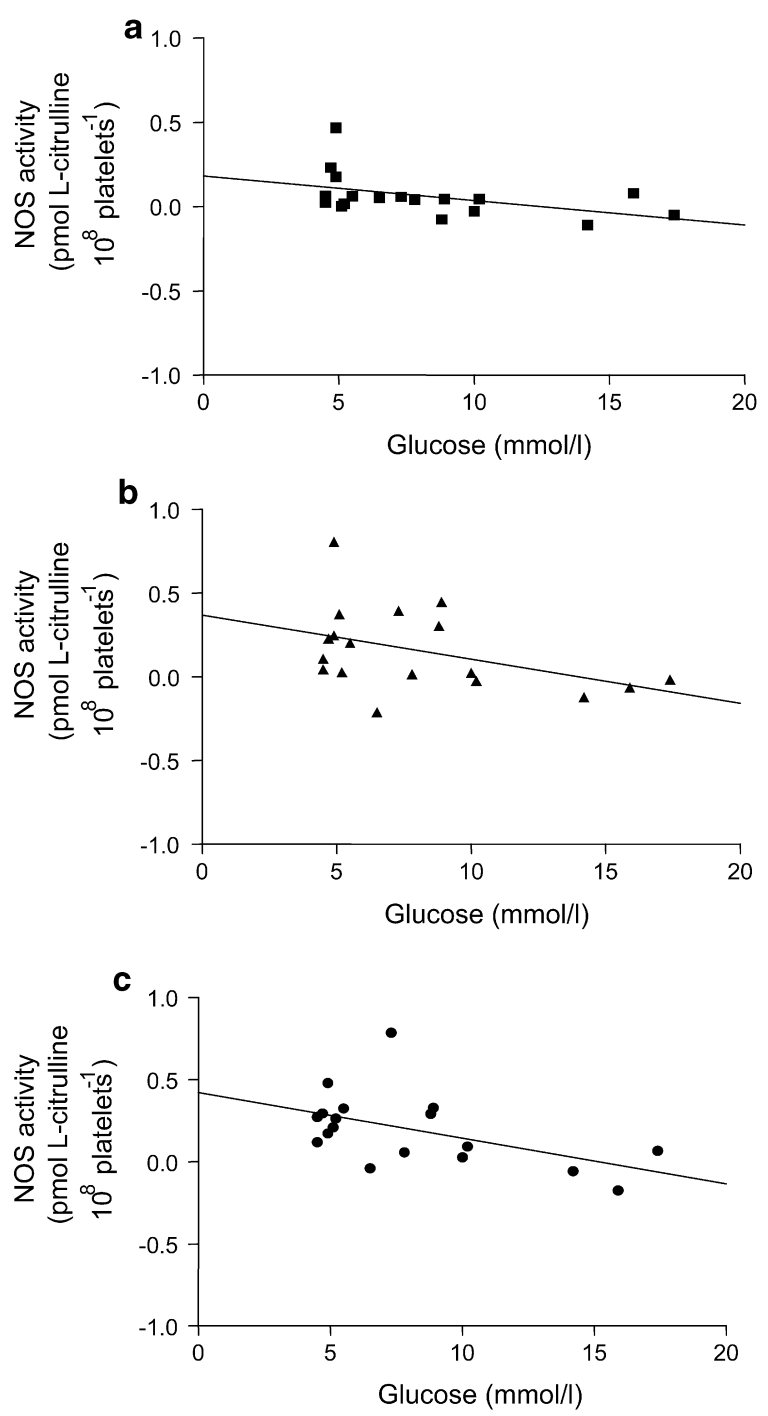

Fig. 5a-c. Linear regression analysis of the relationship between NOS activity and plasma glucose concentration. The figure shows (a) basal $\left(\boldsymbol{\square}, r^{2}=0.21 ; p=0.06\right)$, (b) isoproterenolstimulated $\left(\boldsymbol{\Lambda}, r^{2}=0.18 ; p=0.08\right)$ and $(\mathbf{c})$ forskolin-stimulated (,$\left.r^{2}=0.26 ; p=0.03\right)$ NOS activity in relation to plasma glucose concentration in the 18 subjects studied

was not significantly different between control and Type 2 diabetic subjects (Fig. 7b). Treatment of platelets ex vivo with isoproterenol $1 \mu \mathrm{mol} / \mathrm{l}$ or forskolin $1 \mu \mathrm{mol} / \mathrm{l}$ in the absence or presence of L-NAME $100 \mu \mathrm{mol} / \mathrm{l}$ had no effect on expression of the $130 \mathrm{M}_{\mathrm{r}}$ band, either in the control subjects $(n=6$; Fig. $8 \mathrm{a})$, or in the Type 2 diabetic patients ( $n=6$; Fig. 8 b).

\section{Discussion}

In agreement with previous studies [11, 12], we found that basal NOS activity in platelets from Type 2 diabetic patients was lower than in control subjects. The stimulation of $\beta \mathrm{AR}$ and increased cyclic AMP did not 

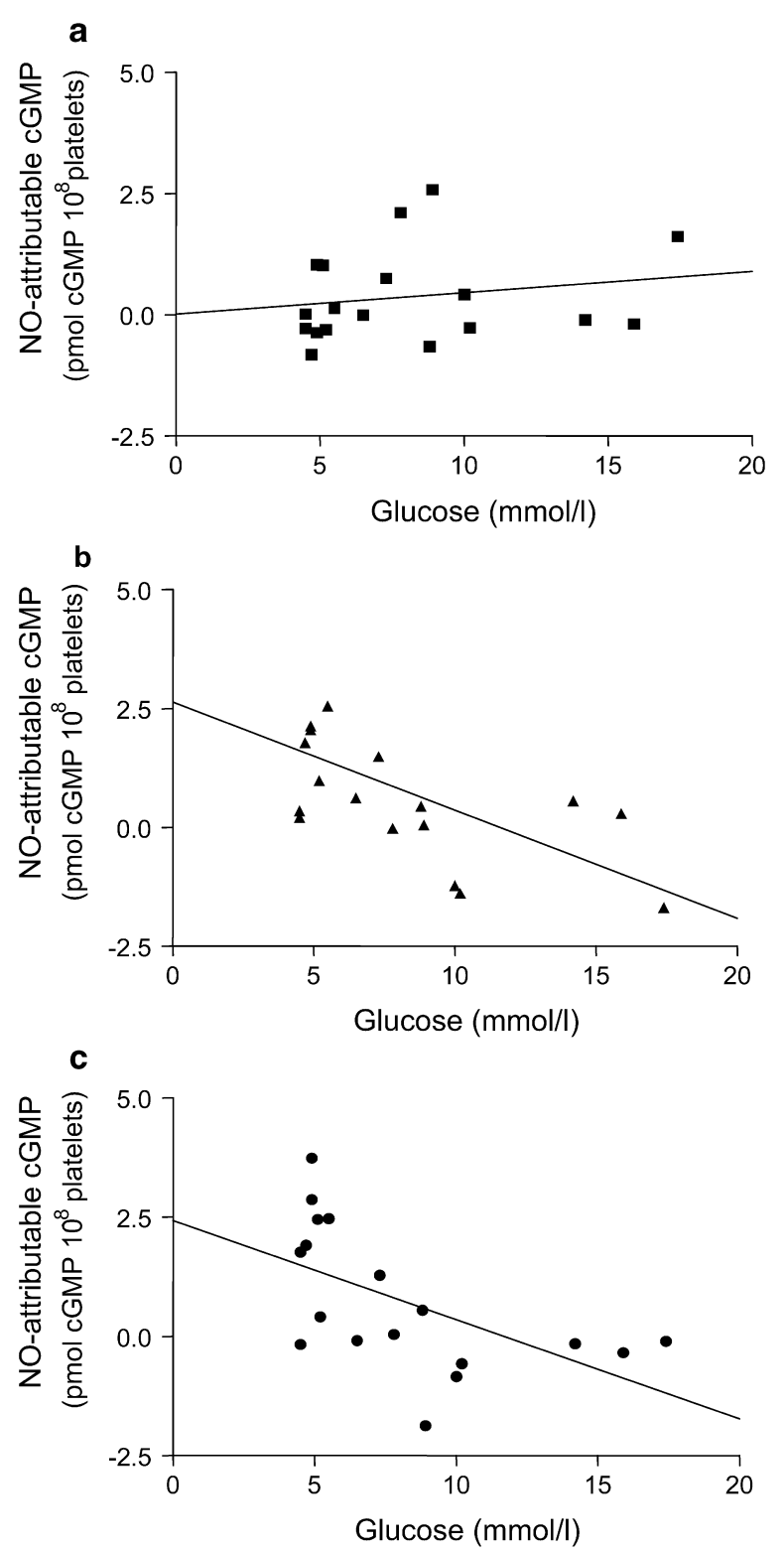

Fig. 6a-c. Linear regression analysis of the relationship between NO-attributable cyclic GMP and plasma glucose concentrations. The figure shows (a) basal $\left(\boldsymbol{\square}, r^{2}=0.03 ; p=0.46\right)$, (b) isoproterenol-stimulated $\left(\mathbf{\Lambda}, r^{2}=0.32 ; p=0.01\right)$ and (c) forskolin-stimulated $\left(\mathbf{O}, r^{2}=0.33 ; p=0.01\right)$ NO-attributable cyclic GMP concentrations in relation to plasma glucose concentration in the 18 subjects studied. CGMP = cyclic GMP

change NOS activity in comparison with basal in platelets from Type 2 diabetic patients. This was in contrast to the situation in platelets from healthy subjects, where noticeable increases in NOS activity were seen in response to isoproterenol and forskolin. In platelets from control and Type 2 diabetic subjects basal cyclic GMP attributable to NO was not noticeably different. In control subjects $\beta A R$ stimulation and elevated cyclic AMP increased intraplatelet cyclic GMP attributable to NO, showing that this pathway can generate bioavailable NO from normal platelets. No such increase of NO-attributable cyclic GMP was

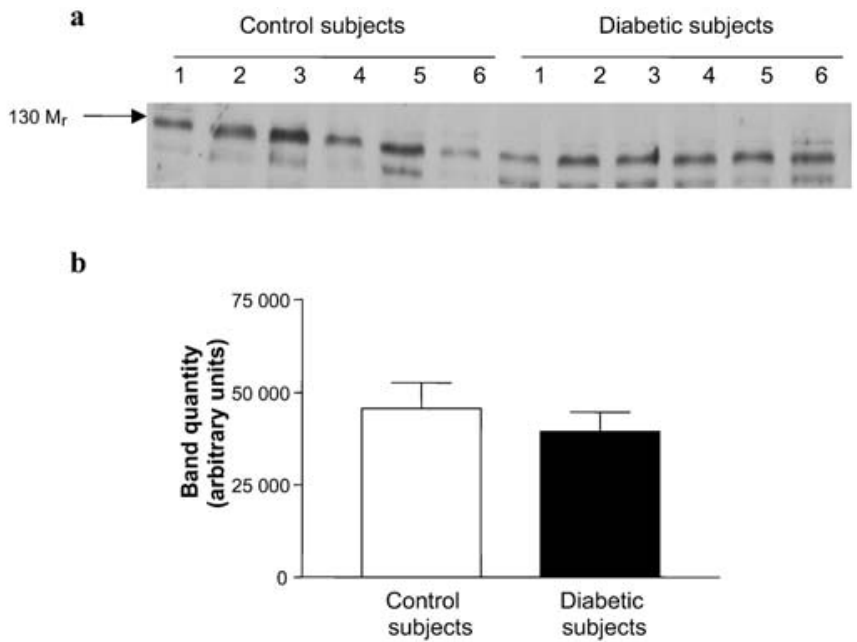

Fig. 7a, b. Quantitation of basal NOS3 expression in platelets from control and Type 2 diabetic subjects. Western blotting using an anti-NOS3 rabbit polyclonal antibody showed a prominent band at $130 \mathrm{M}_{\mathrm{r}}$ in samples from control and Type 2 diabetic subjects (a). This $130 \mathrm{M}_{\mathrm{r}}$ band was quantified densitometrically (b). Values are means \pm SEM of measurements from six control and six Type 2 diabetic subjects
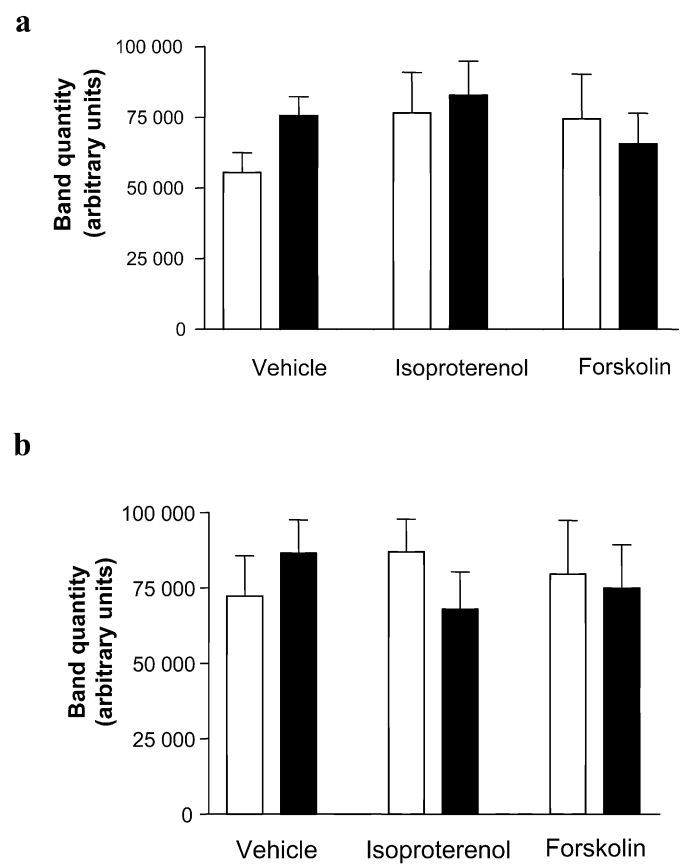

Fig. 8a, b. Western blotting analysis of NOS3 in platelets from control and Type 2 diabetic subjects. The $130 \mathrm{M}_{\mathrm{r}}$ band quantities are shown in control (a) and Type 2 diabetic (b) subjects after treatment with vehicle, isoproterenol $1 \mu \mathrm{mol} / \mathrm{l}$ or forskolin $1 \mu \mathrm{mol} / \mathrm{l}$, in the absence (open bars) and presence (solid bars) of L-NAME $100 \mu \mathrm{mol} / \mathrm{l}$. Values are means \pm SEM of measurements from six subjects in each case

observed in platelets from the Type 2 diabetic group, again indicating that $\mathrm{NO}$ generation by platelets is impaired in these patients.

In contrast to people with Type 1 diabetes, in whom basal cyclic GMP has been shown to be lower 
than in control subjects [10], the Type 2 diabetic patients in our study did not have reduced concentrations of basal cyclic GMP. One possible explanation for this is the insufficient power of our study, due to the low number of subjects studied. Alternatively, Type 2 diabetic patients could differ from Type 1 patients in this regard. However, the NOS assays detected a small but significant decrease in basal NOS activity in Type 2 diabetic subjects in comparison with control subjects, and it is possible that the cyclic GMP assay is less sensitive than the NOS assay in detecting such differences in NO production. Nevertheless, NOS and cGMP responses to isoproterenol and forskolin in control platelets failed to take place in the presence of L-NAME, indicating that stimulation of $\beta A R$ through increased cyclic AMP does indeed stimulate the L-arginine/NO pathway. This pathway was seen to be impaired in the Type 2 diabetic subjects.

Our results also support the hypothesis that, especially under stimulated conditions, decreased NOS activity and hence NO biosynthesis in platelets from Type 2 diabetic patients increase platelet adhesiveness $[21,22]$ and hypersensitivity to aggregating agents seen in this condition [23, 24, 25].

It has been suggested that NOS activity in platelets is related to glycaemic control. A significant inverse correlation between $\mathrm{HbA}_{1 \mathrm{c}}$ values and basal platelet NOS activity has been found in Type 1 and Type 2 diabetic patients [12]. However, a similar study [11] failed to find any such correlation, while another study [10] reported no correlation between basal cyclic GMP and glycaemic control in people with Type 1 diabetes. We found no correlation between $\mathrm{HbA}_{1 \mathrm{c}}$ or plasma glucose and basal platelet NOS activity or basal cyclic GMP attributable to NO. However, $\beta A R-$ and adenylyl cyclase-stimulated cyclic GMP production attributable to NO, as well as NOS activity stimulated by adenylyl cyclase were all inversely correlated with $\mathrm{HbA}_{1 \mathrm{c}}$ and plasma glucose. Furthermore, in short-term in vitro experiments we found that platelets in a high-glucose environment showed no increase in $\mathrm{L}-\left[{ }^{3} \mathrm{H}\right]$-citrulline production in response to isoproterenol or forskolin. Thus, it is likely that poor glycaemic control is in itself an important factor in the impaired $\beta \mathrm{AR}$-mediated NO generation seen in Type 2 diabetic patients. Hyperglycaemia has previously been associated with enhanced platelet activation [26], platelet-dependent thrombosis [27] and increased platelet generation of reactive oxygen species [28], all effects which would be consistent with a decrease in platelet-derived NO production. Other factors present in Type 2 diabetes mellitus, such as obesity, insulin resistance and alterations in lipid metabolism, could also affect NO-dependent platelet function, but we did not investigate these factors.

During the study some of the patients were taking oral hypoglycaemic drugs (metformin and glibenclamide). These have been shown to directly affect platelets, albeit weakly. Metformin decreases platelet superoxide anion $\left(\mathrm{O}_{2}{ }^{-}\right)$production in Type 2 diabetes [29]. Generation of this free radical is known to be increased in diabetes through a variety of mechanisms [30]. $\mathrm{O}_{2}$ - is particularly important as a scavenger of $\mathrm{NO}$, therefore the antioxidant effects of metformin should result in an increase in bioavailable NO-the opposite of what we observed. Glibenclamide blocks thrombin-stimulated $\mathrm{K}^{+}$efflux through $\mathrm{Ca}^{2+}$ - and voltage-gated ion channels in platelets [31] but only at a high concentration $(20 \mu \mathrm{mol} / \mathrm{l})$. The average in vivo serum concentration in diabetic patients is not likely to exceed $150 \mathrm{nmol} / \mathrm{l}$ [32]. Glibenclamide has also been shown to have a weak anti-aggregatory action on platelets [33] and to inhibit isoproterenol- and forskolin-activated $\mathrm{Cl}^{-}$conductance [34], but again both actions only occur at concentrations several times higher than those found in vivo.

To date no effects of diabetes on NOS3 expression in human platelets have been determined. We therefore measured NOS3 expression in platelets taken from control and Type 2 diabetic subjects. Our aim was to determine whether changes in NOS3 expression could account for the observed differences in NOS activation mediated by $\beta A R$ and adenylyl cyclase. Western blotting of platelet lysates confirmed the presence of NOS3 in control and Type 2 diabetic subjects, a result consistent with previous studies [3, $17,35]$. No difference in basal NOS3 expression was found between platelets from control and Type 2 diabetic subjects. Neither $\beta A R$ stimulation nor increased cyclic AMP affected NOS3 expression in platelets from either group. However, this is not surprising as the treatments were of a short duration (up to $40 \mathrm{~min}$ ) and most effects on protein expression occur after several hours. Few studies have investigated NOS3 expression in diabetes, but in steptozotocin-induced diabetic rats endothelial cell NOS3 was increased [20].

Our results suggest that changes in NOS3 expression cannot account for the impaired $\beta A R$ - and adenylyl cyclase-mediated NO generation seen in platelets of people with Type 2 diabetes. An alternative explanation for the findings must therefore be sought. Alterations in $\mathrm{Ca}^{2+}$ signalling have been described in diabetes [36, 37], although this is unlikely to affect $\beta A R-m e d i a t e d$ NOS3 activation, as this activation has been shown to occur without detectable changes in intracellular $\mathrm{Ca}^{2+}$ either in human vascular endothelial cells [38] or in platelets [6]. It has been reported that sheer stress can activate NOS3 in a $\mathrm{Ca}^{2+}$-independent manner [39]. This is due to phosphorylation of the NOS3 serine residue Ser ${ }^{1177}$, which alters the enzyme's sensitivity to $\mathrm{Ca}^{2+}$, enabling maximal activity at sub-physiological concentrations of $\mathrm{Ca}^{2+}$ [40]. It is, therefore, possible that serine phosphorylation of NOS3 in platelets from control subjects is different to that seen in people with Type 2 diabetes. Moreover, 
eNOS can be phosphorylated on threonine and tyrosine residues, which could also regulate NOS3 activity. Phosphorylation of $\mathrm{Thr}^{495}$ is generally associated with a decrease in enzyme activity [41, 42]. While endothelial NO production can be modulated by tyrosine kinase inhibitors and tyrosine phosphatase inhibitors $[43,44]$, little is known about which tyrosine residues are phosphorylated [45]. Thus changes in threonine or tyrosine phosphorylation of NOS3 could also explain our findings.

While confirming previous findings, our study shows that basal platelet NOS activity is considerably lower in Type 2 diabetic subjects than in healthy control subjects and that $\beta A R-$ and adenylyl cyclasemediated NO generation by platelets is suppressed in these patients. This suppression is related to hyperglycaemia and could contribute to the increased platelet aggregation and adhesion seen in the disease. The functional changes observed cannot be explained by changes in NOS3 expression. The mechanism by which $\beta A R-$ and cyclic AMP-induced NO generation is impaired in platelets from Type 2 diabetic patients remains unclear.

Acknowledgements. We would like to thank the Guy's \& St Thomas' Charitable Foundation for financial support.

\section{References}

1. Radomski MW, Palmer RM, Moncada S (1990) An L-arginine/nitric oxide pathway present in human platelets regulates aggregation. Proc Natl Acad Sci USA 87:51935197

2. Radomski MW, Palmer RM, Moncada S (1987) Endogenous nitric oxide inhibits human platelet adhesion to vascular endothelium. Lancet 2:1057-1058

3. Wallerath T, Gath I, Aulitzky WE, Pollock JS, Kleinert H, Forstermann U (1997) Identification of the NO synthase isoforms expressed in human neutrophil granulocytes, megakaryocytes and platelets. Thromb Haemost 77:163167

4. Radomski MW, Palmer RM, Moncada S (1990) Characterization of the L-arginine:nitric oxide pathway in human platelets. Br J Pharmacol 101:325-328

5. Freedman JE, Loscalzo J, Barnard MR, Alpert C, Keany JF, Michelson AD (1997) Nitric oxide released from activated platelets inhibits platelet recruitment. J Clin Invest 100:350-356

6. Queen LR, Xu B, Horinouchi K, Fisher I, Ferro A (2000) beta(2)-adrenoceptors activate nitric oxide synthase in human platelets. Circ Res 87:39-44

7. McVeigh GE, Brennan GM, Johnston GD et al. (1992) Impaired endothelium-dependent and independent vasodilatation in patients with type 2 (non-insulin dependent) diabetes mellitus. Diabetologia 35:771-776

8. Williams SB, Cusco JA, Roddy MA, Johnstone MT, Creager MA (1996) Impaired nitric oxide-mediated vasodilation in patients with non-insulin-dependent diabetes mellitus. J Am Coll Cardiol 27:567-574

9. De Vriese AS, Verbeuren TJ, Voorde J van de, Lameire NH, Vanhoutte PM (2000) Endothelial dysfunction in diabetes. Br J Pharmacol 130:963-974
10. Amado JA, Salas E, Botana MA, Poveda JJ, Berrazueta JR (1993) Low levels of intraplatelet cGMP in IDDM. Diabetes Care 16:809-811

11. Martina V, Bruno GA, Trucco F et al. (1998) Platelet cNOS activity is reduced in patients with IDDM and NIDDM. Thromb Haemost 79:520-522

12. Rabini RA, Staffolani R, Fumelli P, Mutus B, Curatola G, Mazzanti L (1998) Decreased nitric oxide synthase activity in platelets from IDDM and NIDDM patients. Diabetologia 41:101-104

13. Mustard JF, Packham MA (1984) Platelets and diabetes mellitus. N Engl J Med 311:665-667

14. Vinik AI, Erbas T, Park TS, Nolan R, Pittenger GL (2001) Platelet dysfunction in type 2 diabetes. Diabetes Care 24:1476-1485

15. Karlsberg RP, Cryer PE, Roberts R (1981) Serial plasma catecholamine response early in the course of clinical acute myocardial infarction: relationship to infarct extent and mortality. Am Heart J 102:24-29

16. Roth GJ, Hickey MJ, Chung DW, Hickstein DD (1989) Circulating human blood platelets retain appreciable amounts of poly (A)+ RNA. Biochem Biophys Res Comm 160:705-710

17. Mehta JL, Chen LY, Kone BC, Mehta P, Turner P (1995) Identification of constitutive and inducible forms of nitric oxide synthase in human platelets. J Lab Clin Med 125:370-377

18. Kuboki K, Jiang ZY, Takahara N et al. (2000) Regulation of endothelial constitutive nitric oxide synthase gene expression in endothelial cells and in vivo: a specific vascular action of insulin. Circulation 101:676-681

19. Nishio E, Watanabe Y (1996) Glucose-induced down-regulation of NO production and inducible NOS expression in cultured rat aortic vascular smooth muscle cells: role of protein kinase C. Biochem Biophys Res Commun 229:857-863

20. Hink U, Li H, Mollnau H et al. (2001) Mechanisms underlying endothelial dysfunction in diabetes mellitus. Circ Res 88:E14-E22

21. Shaw S, Pegrum GD, Wolff S, Ashton WL (1967) Platelet adhesiveness in diabetes mellitus. J Clin Pathol 20:845-847

22. Hellem AJ (1971) Adenosinediphosphate induced platelet adhesiveness in diabetes mellitus with complications. Acta Med Scand 190:291-295

23. Winocour PD (1992) Platelet abnormalities in diabetes mellitus. Diabetes 41 [Suppl 2]:26-31

24. Kwaan HC, Colwell JA, Cruz S, Suwanwela N, Dobbie JG (1972) Increased platelet aggregation in diabetes mellitus. J Lab Clin Med 80:236-246

25. Sagel J, Colwell JA, Crook L, Laimins M (1975) Increased platelet aggregation in early diabetes mellitus. Ann Intern Med 82:733-738

26. Gresele P, Guglielmini G, De Angelis M et al. (2003) Acute, short-term hyperglycaemia enhances shear stressinduced platelet activation in patients with type II diabetes mellitus. J Am Coll Cardiol 41:1013-1020

27. Shechter M, Merz CN, Paul-Labrador MJ, Kaul S (2000) Blood glucose and platelet-dependent thrombosis in patients with coronary artery disease. J Am Coll Cardiol 35:300-307

28. Yamagishi S, Edelstein D, Du XL Brownlee M (2001) Hyperglycemia potentiates collagen-induced platelet activation through mitochondrial superoxide overproduction. Diabetes 50:1491-1494

29. Gargiulo P, Caccese D, Pignatelli P et al. (2002) Metformin decreases platelet superoxide anion production in diabetic patients. Diabetes Metab Res Rev 18:156-159 
30. Bonnefort-Rousselot D (2002) Glucose and reactive oxygen species. Curr Opin Clin Nutr Metab Care 5:561568

31. Silva HA de, Carver JG, Aronson JK (1997) Pharmacological evidence of calcium-activated and voltage-gated potassium channels in human platelets. Clin Sci (Lond) 93:249-255

32. Jonsson A, Hallengren B, Rydberg T, Melander A (2001) Effects and serum levels of glibenclamide and its active metabolites in patients with type 2 diabetes. Diabetes Obes Metab 3:403-409

33. Siluk D, Kaliszan R, Haber P, Petrusewicz J, Brzozowsk Z, Sut G (2002) Antiaggregatory activity of hypoglycaemic sulphonylureas. Diabetologia 45:1034-1037

34. Tominaga M, Horie M, Sasayama S, Okada Y (1995) Glibenclamide, an ATP-sensitive $\mathrm{K}+$ channel blocker, inhibits cardiac cAMP-activated $\mathrm{Cl}^{-}$conductance. Circ Res 77:417-423

35. Chen LY, Mehta P, Mehta JL (1996) Oxidised LDL decreases L-arginine uptake and nitric oxide synthase protein expression in human platelets: relevance of the effect of oxidized LDL on platelet function. Circulation 93:1740 1746

36. Mazzanti L, Rabini RA, Faloia E, Fumelli P, Bertoli E, De Pirro R (1990) Altered cellular $\mathrm{Ca}^{2+}$ and $\mathrm{Na}^{+}$transport in diabetes mellitus. Diabetes 39:850-854

37. Schaeffer G, Wascher TC, Kostner GM, Graier WF (1999) Alterations in platelet $\mathrm{Ca} 2+$ signalling in diabetic patients is due to increased formation of superoxide anions and reduced nitric oxide production. Diabetologia 42:167-176
38. Ferro A, Queen LR, Priest RM et al. (1999) Activation of nitric oxide synthase by beta 2 -adrenoceptors in human umbilical vein endothelium in vitro. $\mathrm{Br} \mathrm{J}$ Pharmacol 126:1872-1880

39. Corson MA, James NL, Latta SE, Nerem RM, Berk BC, Harrison DG (1996) Phosphorylation of endothelial nitric oxide synthase in response to fluid shear stress. Circ Res 79:984-991

40. Dimmeler S, Fleming I, Fisslthaler B, Hermann C, Busse R, Zeiher AM (1999) Activation of nitric oxide synthase in endothelial cells by Akt-dependent phosphorylation. Nature 399:601-605

41. Fleming I, Fisslthaler B, Dimmeler S, Kemp BE, Busse R (2001) Phosphorylation of $\operatorname{Thr}(495)$ regulates $\mathrm{Ca}(2+) /$ calmodulin-dependent endothelial nitric oxide synthase activity. Circ Res 88:E68-E75

42. Chen ZP, Mitchelhill KI, Michell BJ et al. (1999) AMPactivated protein kinase phosphorylation of endothelial NO synthase. FEBS Lett 443:285-289

43. Fleming I, Bara AT, Busse R (1996) Calcium signalling and autacoid production in endothelial cells are modulated by changes in tyrosine kinase and phosphatase activity. J Vasc Res 33:225-234

44. Fleming I, Bauersachs J, Fisslthaler B, Busse R (1998) $\mathrm{Ca} 2+-$ independent activation of endothelial nitric oxide synthase in response to tyrosine phosphatase inhibitors and fluid shear stress. Circ Res 82:686-695

45. Fleming I, Busse R (2003) Molecular mechanisms involved in the regulation of the endothelial nitric oxide synthase. Am J Physiol 284:R1-R12 